\title{
Discussion on Principles of Case Teaching with Five Years' Experience
}

\author{
Hongwei Zhou \\ Information Engineering University \\ Zhengzhou, China
}

\author{
Jinhui Yuan* \\ Sias International University \\ Zhengzhou, China
}

\begin{abstract}
Someone consider that case teaching is a miraculous medicine to improve teaching effectiveness. However, in my opinion, it is wrong. In past five years, we have implemented case teaching repeatedly in our class. At the first attempt, the effectiveness is not good. To improve it, we begin to carefully study the methods to implement case teaching. Through five years experience, we hold some new ideas about case teaching. In this paper, we discuss the principles of case teaching which is the sum up of our experience. We believe that they are helpful to implement case teaching in the university education.
\end{abstract}

Keywords-Case Teaching; Teaching Effectiveness; Evaluation Standard; Case discussion

\section{INTRODUCTION}

Case teaching has become an important means of teaching. Case teaching method is a kind of case-centered teaching method. On the teaching purpose, case teaching puts forward the corresponding case for students' independent study or discussion in the groups, so as to improve the students' ability to analyze and solve the problems. The traditional teaching method pays attention to the teaching of the knowledge, and the teachers is the center of teaching. Compared with the traditional teaching methods, case teaching requires the students to analyze and reflect on themselves, and explore the methods to solve problems. At present, case teaching has been widely used in the field of education.

At present, many colleges and universities in China are promoting teaching reform to improve the teaching quality. In order to make up for the shortcomings of traditional education methods, case teaching has also been introduced into the teaching reform. We also try to introduce case teaching into the teaching activities in the movement. After five years of practice, we have gained the experience of the methods of implementing case teaching, and have some own views about how to organize case teaching. Based on our teaching experience, this paper discusses some basic principles of case teaching method and our opinions.

\section{CASE Teaching Is Not A Wonderstruck Medicine}

Case teaching is not a miraculous medicine to improve teaching effectiveness. In this wave of teaching reform, every teacher is looking for feasible methods to improve the teaching effectiveness. Because of the interesting and enlightening of case teaching, people quickly noticed case teaching, and found the advantages of case teaching in a large number of documents. Therefore, many teachers have introduced case teaching into their own classroom, and they hope that the introduction of case teaching can immediately improve the teaching effect. However, the effect is not what they expect. Case teaching is just a means of teaching with its characteristics and applicable scope [1]. Case teaching is not a panacea for anything.

A successful example of case teaching is the Law School of Harvard University. It requires the students to read the real case and judge comments on case. Furthermore the students analysis, reason and judge the method of the judge. Finally they will use the reasoning and judgment method to a similar case. But Harvard University does not require all classes to use case teaching methods. This also shows that not all of the course content is suitable for case teaching. Not all of the teaching content is suitable for case teaching. At present, there is an extreme situation. When the advantages of case teaching are introduced by the public opinion, we all think that the case teaching method is very good and want to use this method in teaching. However, it doesn't bring enough teaching effect in reality.

This leads to a new question: what kind of teaching content is suitable for case teaching? Case teaching has a basic assumption that the students can learn through case analysis, research and discussion, and apply relevant knowledge and skills to solve the similar problem. Case teaching is very suitable for developing, analyzing, synthesizing and evaluating teaching contents. One of the salient features of these teaching materials is that they are often uncertain. This uncertainty makes the students who are accustomed to traditional teaching feel confused. They have used to that one problem only has one exact answer. The case teaching is just suitable for such teaching content. With the case, the students have a better understanding of the solve methods and the cause that there are so many solve methods to the same problem. In a short word, a case is a story without the only answer [2].

When we first introduce case teaching into the curriculum, we plan to implement most of the teaching content in the form of case teaching. However, the reality is that our teaching effect is not good. After finishing the class, we carefully analyze the teaching content, and we found that some of the teaching content is not suitable for case teaching. Sometimes, in order to carry out case teaching in inappropriate teaching content, we have to start teaching with the inappropriate cases. 
However, for case teaching, an appropriate case is the basic guarantee of the effectiveness of case teaching. This led to the failure of our first case teaching in 2013. In our opinion, teaching reform does not means that we have to change the teaching method. Case teaching is an excellent method, but is not miraculous medicine for anyone or anything.

\section{CASE Teaching ReQuiRes Teachers to DeVote MORE TIME TO IT}

One wrong view is that case teaching is a way for teachers to be lazy. The cause is the teacher does not need to teach the curriculum content continuously in the case teaching. The students take up part of the time to analyze and discuss the problems. This gives the illusion that when teachers organize case teaching, and they are in a state of leisure. Thus some of the students think that the teachers don't want to spend too much time in class. And they consider also that the student completes what the teacher should do for the students, and it is irresponsible. Of course, that's not the case.

In order to ensure the effectiveness of case teaching, the teacher needs to spend more time preparing. In the traditional teaching, the teaching content is relatively fixed, teachers can always hold the rhythm and content of the teaching, so teachers can easily estimate the content of teaching and students may be involved in the problem. In case teaching, the students' thinking is divergent, and the teaching activities are often not as complete as the teacher intended. The teacher can not accurately predict the problems that students may encounter. In order to ensure the quality of case teaching, teachers must spend more time, consult more relevant information, expand the relevant knowledge as much as possible, in order to deal with the possible problems of students. As a teacher, you also have to tell the students what materials to be read [3]. Moreover you have to read them in advance. So it is impossible to prepare the case teaching in the short time.

Case teaching requires a lot of time to prepare. In our teaching process, we are also accumulated our experience step by step. When we first introduce case teaching into teaching activities, there is a lack of preparation. On the one hand, a considerable part of the teaching content is taught in the form of case teaching. On the other hand, the preparation of individual case teaching is inadequate. After summing up the experience and lessons of the first case teaching, we organized the relevant personnel to carry out case teaching preparation in the second teaching, and further prepared the teaching content around the case teaching content. In the second teaching activities, the teaching effectiveness has been significantly improved. In view of this, our teaching group, after each teaching activity is completed, according to the teaching feedback, further prepares the relevant cases.

In the case of single case teaching, it is often necessary to practice repeatedly to have good teaching effectiveness. As mentioned earlier, the thinking of students in case teaching is very active, so there are new ideas to be appeared. Some ideas are even beyond the scope of teachers' presupposition, so that the teachers can not perfect interpretation of the ideas to the students the background. They need to refer to the more material. And, over time, some new characteristics of the times will push on the case. The teachers also need time to come to a more profound understanding of the case. So even if the teaching of the same case, often will take many years of repeated, there will be a more perfect teaching program. In a word, case teaching is not a promotion, but requires the teachers to invest more time and energy than traditional teaching to complete the teaching preparation.

\section{Teachers AND Students CONTRIBUte to TeACHING EFFECT}

The teachers and students contribute to teaching effectiveness of case teaching. In the traditional teaching method, the teachers are the main activities. In case teaching, the students become indispensable participants, and they must express their views [4], at this time, students are no longer passive participants, they will be the subject of case teaching. If students do not actively participate in the case teaching, the case teaching will undoubtedly fail. As a teacher, must be targeted to guide students to participate in the case teaching. Both teachers and students need to pay more energy than traditional teaching to guarantee the effectiveness of case teaching.

There is an old saying that wisdom is not acquired by others. The basic knowledge can be acquired by teachers, but the basic knowledge is no longer enough to solve the problems in real life. It is particularly important to master the knowledge, to apply the knowledge, and master the skills of dealing with new problems. Case teaching can be used to train students for the ability. Moreover, this ability is not taught by the teacher, and the students gain it in case analysis, discussion process. This requires students to take the initiative to cooperate with teachers in the implementation of case teaching. Only when the students really put in the time to consult the materials, speak actively and think actively, can they gain in the case teaching.

The teachers need to encourage the students to participate in case teaching. First, the teachers should set up a set of effective evaluation standards to encourage the students to participate in case teaching. Evaluation should cover all aspects of case teaching, including preparation before class, class discussion, and after class. In our opinion, the method of evaluation should be objective and quantitative, and all the evaluation standards should be published before the evaluation, and the evaluation results of the indicators should be promptly disclosed. Second, the introduction of students in some aspects of the evaluation process, not only can guarantee the fairness of the evaluation results, but also can further stimulate the students. Our approach is to grade the students anonymously in the classroom, and ask them to grade the solutions, the discussions, and the discussion summaries. The students in the evaluation process, once again learn the ideas of other students, and compared with their own views, no doubt can sublimate the learning results. The fairness and justice of evaluation can make the students to participate in case teaching with an active attitude.

The teachers also need to guide the students to discuss in case teaching. First, the size of the group should not be too much or too little. The two extremes are not conducive to the implementation of case teaching. Second, the topic of 
discussion should be deviate from original one. When the students discuss in their views, it is possible that the topic of discussion is deviated. In this time, the teachers need to guide the students to speak the right direction. Finally, the teacher should summarize the results of the discussion in time to ensure that the students find valuable conclusions on the various speeches. Of course, it does not mean that the teachers should give a unique answer to the questions discussed, but it is necessary to evaluate the appropriateness of various solutions, otherwise it will lead to students' confusion.

\section{CAse Teaching Should Break Restriction}

Case teaching is a means different from the traditional teaching [5], and it may break the constraints of traditional teaching. This breakthrough, for some teachers, may be necessary and effective. But for some other teachers, it is in the sensationalism. When we try to show a case in the form of sketch in the classroom, some teachers feel unnecessary. They think that it may be a farce because the students are not good at performing. However some teachers think that it may lead to laughter, but it successfully guides the students into the role of thinking. In our opinion, break the traditional teaching constraint is necessary, but should be cautious and careful.

The most common breakthrough is the meeting room. In traditional teaching, the teachers usually teach on the platform, while students sit their chair and listen to them. But it is not appropriate for the discussion. In our opinion, the discussion staff should be able to look directly. If the students are still in accordance with the order in the seat, the discussion is unable to meet the direct rule. So the discussion scene is often all sitting around the table. However, most of the existing classrooms are not satisfied with this condition. One way to compromise is to adjust the tables and chairs. But the placement of desks and chairs in classrooms is not completely acceptable. Some teachers think that the next course is affected, while others believe that the classroom time will be placed desks and chairs. But it is necessary to arrange the discussion room as reasonably as possible.

Case teaching should be a variety of forms. First, the cases should be in various forms. The case can be dictated by the teacher, or it can be presented in a printed document, or it can be video or live performance. We don't think which form of case is most appropriate, which depends on the class arrangement and the content of the case. There are various forms of the discussion, which can be both forms of debate or statements of each group. Case evaluation can also be carried out in many methods, which is evaluated by teachers, by students participating in evaluation, and by constructing multi factor evaluation standards and so on. According to the teaching content and teaching arrangement, we should prepare carefully.

\section{GOOD CASE IS THE FOUNDATION OF SUCCESS}

Case teaching is a case-centered teaching method [6]. In case teaching, the case is a medium for teachers and students to communicate with each other. Good cases are the foundation for good teaching effectiveness. If the case used in the case teaching is not appropriate, it will make it difficult for the teacher to complete the knowledge transfer through the case, and the students can not carry out reasonable self learning. The bad cases can not play the role of a bridge of knowledge transmission in the case teaching. Instead, students feel confused and fail to achieve the purpose of learning.

Teachers have to find the right cases with the patience. Some cases correspond to the teaching content may be more popular, so the teachers are easy to find the appropriate cases from reality. For example, in real life, there is a large number of academic conferences, and the organizers also talk about the method to organize the conference. So the cases are easy to be collected. In some cases, on the contrary, the teaching content of the corresponding is relatively uncommon, and the cases are virtually unknown. This makes the teacher have to be patient and look for the right cases. Only by retaining the desire for a case can we find interesting things in everyday life and various materials, and then organize and process, and eventually gain useful cases, which should be used in case teaching.

It takes a lot of time for teachers to build the cases set to support a course. Since we started with case teaching methods, we spent about five years building a case set for our course. We had hoped that several teachers would collaborate to build a case set in a short time. But contrary to our expectations, the cases we used in our first teaching were not always appropriate, and the teaching effectiveness was not satisfactory. So we have to adjust the cases in the set after class, and removed inappropriate cases, and modified inappropriate parts. We have statistics, after the first implementation of case teaching, only about $30 \%$ of the cases are retained. Since then, every year we revise and improve the case set according to the teaching effectiveness and students' feedback. After several years, we have initially established a case set that can support the teaching of courses.

Discovering the suitable cases requires a keen eye. We often feel that the case is everywhere, but the right case is hard to get, which requires the teacher has a keen eye. In order to find a good case, the teacher should always pay attention to the actual things related to the teaching content. Once an appropriate event that can be used as a case is found, the teacher traces and digs the case to make the case full. There is an example that we find a suitable case about sample survey. At that time, just as the United States presidential election, the polls showed Hillary Clinton would be elected, but the result was the opposite. We take this incident as the background of the sample survey and guide the students to analyze the reason why the survey results lead to the difference between the sample survey results and the actual results. After a complete case study, we compiled the relevant material to form the case named as "Sample Survey Accuracy: Why Hillary Clinton Lost Election". In the second year of teaching, we used this case in the teaching, and obtain a good teaching effectiveness. We think teachers must have a keen eye and are good at discovering the cases related to teaching content. 


\section{TeACHER ShOUld Be A GoOd Playwright}

Real life cases often fail to be directly used in classrooms. For some courses, it may be possible to directly use some reallife cases, such as the judge cases used by law schools. But for some teaching content, the direct use of the actual case is not the best choice. There are some reasons listed as follows. First, the actual case involves a large number of irrelevant content, which interferes with students' learning. Second, the actual cases may not cover the teaching content completely, and the case study will result in the lack of some teaching content. In order to ensure the teaching effectiveness of case teaching, it is necessary to rewrite the cases according to the actual cases.

The process of writing a case is also the process of collecting relevant information by the teacher. Before the case discussion, the teacher needs to provide a reference for the students. These data should be closely related to the case. Only when teachers read, analyze and think about these materials, they can provide the most valuable reading materials for students. Otherwise, students may spend a lot of time looking for information, which is not very helpful. Under the premise of reading a lot of relevant information, the teacher is likely to respond to divergent thinking of students. When the students access to other materials on the basis of the information provided by the teacher, they may propose new problems, and the answers may be in the relevant data collected by the teacher.

In the process of writing a case, it is also the process of the teacher's arrangement of teaching ideas. In the creation of cases, teachers often need to integrate a number of actual cases of material, in order to write a case for teaching. In the process of thinking and analysis, the teacher will have some new teaching ideas, but also find a new solution on the case. As mentioned earlier, the case is a little story without the only answer. So, when a teacher creates a case, he must presuppose a variety of endings, and compare the merits of each ending.

In a word, writing a case is just writing a script, and a teacher should be a good playwright. In order to write a play, the playwright needs to experience life, draw inspiration from life, and then carry out intensive processing so as to write an excellent play. Writing a case is a similar situation. In order to write a case, the teacher must also find the relevant cases, and remove the irrelevant content, improve the useful content. At last, they present the cases suitable for teaching. In essence, this is the process of creating a script.

\section{GOOD ORGANIZER IS INDISPENSABLE FOR CASE DISCUSSION}

Case discussion is the key of case teaching. Whether the case discussion is successful or not is directly related to the effect of case teaching. According to the general process of case teaching, students usually complete the corresponding case preparation before the case discussion, and finish the discussion summary after the case discussion. In our opinion, case discussion can be used to verify the preparation of students' case discussions. Moreover it is the chance for students to exchange their ideas, and acquire new knowledge, and verify new content. If there is no successful case discussion, case teaching will become self-study, which can not achieve the effectiveness of sublimation of knowledge.
As the organizer of the case discussion, the teacher is the key to the success of the case discussion. If the organizer of the case discussion is unfamiliar with the cases and the background of the cases, then the case discussion is difficult to succeed. When the teacher has the knowledge reserves, it does not mean that the case discussion is certain to be successful. As the organizer of the discussion, the teacher also needs to know some skills. For example, before the discussion, a small number of students are allowed to speak in advance, and the atmosphere of discussion is activated so that other students can easily enter the roles of the discussion. In the process of discussion, attention should be paid not to deviate from the theme, so as to avoid the discussion ineffective, and then arouse students' disgust, so as not to participate in the discussion.

In some case discussion, some students are not actively involved in the discussion. Maybe the reason is that the students are not prepared for the discussion, or the students are not willing to participate in the discussion. At this time, teachers need to actively guide, adopt various measures to enable students to actively participate in the discussion. A direct method is to bring the discussion preparation and the performance of the discussion process into the assessment to encourage students to participate in the discussion. The teacher should also pay attention to guide the students in the discussion, and roll call is also a means. For example, in a case teaching process of organizing a meeting, the teacher directly calls a student who organized a student meeting to speak. Obviously it will get twice the result with half the effort.

\section{CONCLUSION}

Case teaching greatly reduces the gap between reality and teaching, so that students can quickly apply the main points of knowledge learned to teaching to solve the problems encountered in reality. Because of this, case teaching is rapidly promoted. Although case teaching is not a miraculous medicine. The teachers have to pay more attention to prepare the case teaching. Moreover, the teachers and the students contribute to teaching effect in case teaching. Case teaching should be based on the characteristics of teaching content and students with the guidance of the teachers. Thus case teaching can play the original effectiveness.

\section{REFERENCES}

[1] Kathy Carter, Rick Unklesbay. Cases in teaching and law [J]. Journal of Curriculum Studies, 1989, 21(6):527-536.

[2] Merseth K K. The Case for Cases in Teacher Education. [J]. Case Method, 1991:42.

[3] Athos A G. Contingencies Beyond Reasoning [J]. 1979, 4(2):7-12.

[4] Erskine J A, Leenders M R, Mauffette-Leenders L A. Teaching with cases [J]. Teaching with Cases, 1998.

[5] Böcker F. Is Case Teaching More Effective than Lecture Teaching in Business Administration? An Exploratory Analysis [J]. Interfaces, 1987, 17(5):64-71.

[6] Zhang R L, Zhang X L, Jin Y E. Case Teaching Method and its Application [J]. Journal of Guilin University of Electronic Technology, 2004. 